\title{
Participation of a Smart Community of Consumers in Demand Response Programs
}

\author{
Omid Abrishambaf, Pedro Faria, Zita Vale \\ GECAD - Knowledge Engineering and Decision Support Research Centre, Polytechnic of Porto (IPP), Porto, Portugal \\ ombaf@isep.ipp.pt, pnf@isep.ipp.pt, zav@isep.ipp.pt
}

\begin{abstract}
The penetration of renewable energy resources and demand response programs causes several management issues, such as network instability. Several research projects are currently investigating and surveying several methods to enhance the network reliability. This paper represents a smart model of community grid that contains a central management unit and several consumers, producers and prosumers. In the proposed model, the community manager is able to control the consumption and generation of the resources by establishing contracts with its members. The community manager utilizes a single period optimization problem for minimizing its operation costs by applying different types of demand response programs and the use of renewable resources. In the case study, an internal low voltage distribution network of a real university campus is considered as the community grid, in order to test and validate the proposed model.
\end{abstract}

Index Terms - Community Grid, Demand Response, Renewable Resources, Optimization problem, Decision tree.

\section{INTRODUCTION}

Demand Response (DR) programs become a reality in the nowadays electricity networks, especially in smart grids and microgrids. Direct Load Control (DLC) as incentive-based and Real-Time Pricing (RTP) as price-based are two useful DR tools for the network operator in order to manage the consumption in demand side [1].

In this concept, the end-users tend to participate in such programs in order to reduce their electricity bills by shifting their high consumption appliances to the off-peak hours [1]. The utilization of DR program from the network operator stand point, brings the efficiency, flexibility, and reliability in the consumption and generation resources management [2].

Moreover, the integration of the DR program and the Distributed Renewable Energy Resources (DRERs) in the distribution level, is a key role in the smartgrid [3]. This means the consumers not only would be able to supply their local demand through their own generation resources, but also, they can sell energy to the network when it is available [4].

Currently, most of the implemented DR programs are procured for the large-scale resources. It is clear that such programs are efficient for the large-sized generators, however, the small-scale, specially home-scale, generation resources are

This work has received funding from the Project NetEffiCity (ANI|P2020 18015), and from FEDER Funds through COMPETE program and from National Funds through FCT under the project UID/EEA/00760/2013. not applicable in these programs [5]. In order to overcome this issue, several concepts have been proposed. Curtailment Service Provider (CSP), and Virtual Power Player (VPP) are two main concepts, that aggregate small-scale DR and DRERs and participate them in the market as one [6]. However, a more reliable and flexible aggregation models are essential.

This paper proposes a smart community grid model that contains consumers, producers, and prosumers. The consumers in this model are residential houses, commerce facilities, and factories, and the producers are Photovoltaic (PV) and wind turbines. In this model, it is considered that a Community Manager (CM) is able to control the consumption and generation of resources who establish contract with this unit, as detailed in Fig. 1.

Moreover, a single period optimization problem is developed in this paper in order to minimize the operation costs of the CM. In the optimization problem, several decision trees will be implemented by utilizing the classregtree function of MALTAB ${ }^{\mathrm{TM}}$. In the presented model, the CM always tends to balance the consumption and generation rates by using the local energy resources in order to avoid purchasing energy from the electricity market.

There are several similar works focused in this area. [7] developed a multi-objective optimization model for load scheduling of demand side consumers, which considers firstly to minimize the energy costs and secondly to maximize its utility measured by a certain utility function. In [8], the authors provided a review on the demand side consumption optimization as well as an outlook on the implemented projects in this context. [9] proposed a linear optimization problem considering mixed-integer programming in order to minimize total energy cost of a microgrid, by implementing optimal resources scheduling results in the microgrid players. However, the main focus of this paper is given to the resource scheduling of the community grid and demonstrate the impact of using DR and DRERs in the community members by employing the proposed optimization problem.

After this section, the smart local community concepts are explained in Section II. The demand response programs used in the paper will be described in Section III. Section IV provides the proposed case study and its results, and finally, Section V clarifies the main conclusions of the work. 


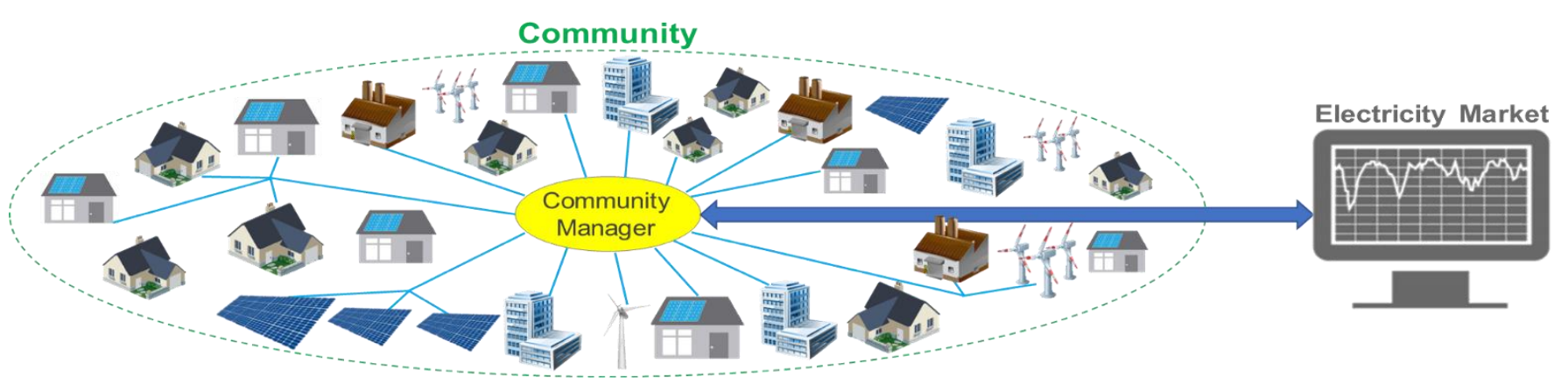

Fig. 1. Overview of the proposed model for the smart community grid.

\section{SMART COMMUNITY GRID}

In this part, at first, the proposed model regarding the community grid will be described, and then, the developed optimization model used by the main controller unit of the community will be explained.

\section{A. Community Characteristics}

A local community grid is related to a group of consumers, producers, and prosumers that some of them have contract with a central controller unit called Community Manager (CM), in order to be controlled and organized by this unit. The differences between a community and an aggregator is that a community has less number of grid players, however, an aggregator has significant number of player. Also, the community is interest based, however, the aggregator is profit based.

The model presented in this paper is an advanced model of the work developed by authors in the scope of previous works [10]. As Fig. 1 illustrates, the producers of the community model proposed in this paper, are DRERs including PV and wind generation, and the prosumers are the consumers who are equipped with PV arrays. In fact, a prosumer is able to supply its electricity demand by its own generation and inject the surplus of production to the community grid. In this network, the $\mathrm{CM}$ is not owning any resources of the grid. However, it only manages the consumption and generation of the whole community, by providing some strategic planning, namely DR programs or resource scheduling, to the players. The CM always tends to supply the demand of the players by DRERs available in the community as well as the surplus of production of the prosumers, in order to avoid purchasing energy from the electricity market. Additionally, the CM is able to sell electricity to the market, while it has generation more than the consumption of community.

If a network player tends to be a community member, it should make a contract with the CM. For this purpose, there are several types of contracts that can be established between the community members and the CM, which are based on the type of the members:

- For producers: they always would be responsible to generate electricity and offer it to the CM, and in exchange, receive payments from the $\mathrm{CM}$, based on the tariffs mentioned in the contract;

- For consumers: they would be accountable to execute $\mathrm{DR}$ programs provided by the $\mathrm{CM}$, and receive incentives based on consumption reduction/curtailment. It is possible for each member to have more than one DR contract.

- For prosumers: they would be responsible to offer the surplus of their generation to the CM, and execute DR programs provided by the CM. In exchange, they will receive payments for the surplus of their generation, as well as incentives for DR participations.

This community model can be considered as a small town or a village where there are several DRERs (producers), and residential houses, factories, and small commerce facilities (consumers or prosumers) who establish contract with the local electricity distributer (CM). All CM members are obligated to transmit their consumption and generation rates as well as the contractual amount of DR to the CM. By this way, the $\mathrm{CM}$ would able to calculate and manage the total energy consumption and generation for the optimization purposes.

\section{B. Optimization Problem}

As it was mentioned, the CM always tends to supply the local demand from its available DRERs and avoid buying energy from the electricity market. For this purpose, the CM should be intelligent enough for managing and scheduling the loads and resources. Therefore, an algorithm has been designed for the CM in order to minimize its Operation Costs (OC). The objective function of this optimization problem is shown on Equ. 1.

$$
\begin{aligned}
& \text { Minimize } \\
& \qquad \begin{array}{l}
\text { OC }=\left(P_{\text {Buy }} \times C_{\text {Buy }}\right)-\left(P_{\text {Sell }} \times C_{\text {Sell }}\right) \\
+\sum_{m=1}^{M}\left(\left(P_{\text {DRER Surplus }(m)} \times C_{D G}\right)\right. \\
\left.+\sum_{t=1}^{T}\left(P_{D R(m, t)} \times C_{D R(m, t)}\right)\right)
\end{array}
\end{aligned}
$$

Where $P_{B u y}$ is the power that CM purchased from the market, and $P_{\text {Sell }}$ is the injected and sold power from the CM to the market. Similarly, $C_{B u y}$ is the price of the power that $\mathrm{CM}$ requested from the market, and $C_{S e l l}$ is the cost that is paid from the market to the CM for the injected power. $M$ stands for the number of the community member. $P_{D R E R}$ Surplus $(m)$ presents the excess of the generated power by each prosumer, and $C_{D G}$ is the cost that the CM should pay to the prosumer for the injected power. Finally, $T$ is the number of DR contract for 
each member, $P_{D R(m, t)}$ represents power reduction/curtailment of each member for each DR contract, and $C_{D R(m, t)}$ is the incentives paid by the $\mathrm{CM}$ to the member. Moreover, the constraints of the proposed optimization problem are:

$$
\begin{aligned}
& P_{\text {Buy }}+\sum_{m=1}^{M}\left(P_{\text {DG Surplus }(m)}+\sum_{t=1}^{T} P_{D R(m, t)}\right) \\
& =\text { Load }+P_{\text {Sell }} \\
& P_{\text {DRER Surplus }(m)} \\
& = \begin{cases}P_{\text {DRER }(m)}-P_{\text {Cons }(m)} & P_{\text {DRER }(m)}>P_{\text {Cons }(m)} \\
0 & P_{\text {DRER }(m)} \leq P_{\text {Cons }(m)}\end{cases} \\
& \forall 1 \leq m \leq M \\
& P_{D R(m, t)} \leq P_{D R(m, t)}^{\max } ; \forall 1 \leq m \leq M, \forall 1 \leq t \leq T \\
& P_{D R E R(m)} \leq P_{D R E R(m)}^{\max } ; \forall 1 \leq m \leq M \\
& P_{\text {Buy }} \leq P_{\text {buy }}^{\max } \\
& P_{\text {Sell }} \leq P_{\text {Sell }}^{\max }
\end{aligned}
$$

This optimization algorithm is considered as a Linear Problem (LP), which in the case study, it is solved through the several decision trees implemented by classregtree function of MATLAB $^{\mathrm{TM}}$.

\section{DEMAND RESPONSE PROGRAMS}

Since the CM is the main core of the community, it is responsible to organize and preserve the balance between the consumption and generation of the members. Moreover, the $\mathrm{CM}$ is able to have energy transaction with the electricity market. However, as far as possible the CM tends to supply the demand from the local resources. That is why it is affordable for the CM to pay incentives to the customers to reduce their consumption instead of purchasing energy from the market. For this purpose, the CM defines several DR programs in order to be applied in the consumers and prosumers. There are six different DR programs designed in this paper, as Table 1 shows. There are three main categories of DR programs: Direct Load Control (DLC), Reduction (Red.), and real-time pricing (Pricing). The community members are able to establish more than one DR contract with the $\mathrm{CM}$ based on their automation infrastructures.

Table 1. DR program contracts offered by $\mathrm{CM}$ to the community members ( $\mathrm{M}=$ Mandatory; $\mathrm{V}=$ Voluntary).

\begin{tabular}{|l|c|c|c|c|}
\hline $\begin{array}{c}\text { DR } \\
\text { Type }\end{array}$ & M/V & Remuneration & $\begin{array}{c}\text { Activation/ } \\
\text { Signal }\end{array}$ & $\begin{array}{c}\text { Measure/ } \\
\text { Contract }\end{array}$ \\
\hline $\begin{array}{l}\text { DLC } \\
\text { T1 }\end{array}$ & M & Power tariff discount & $\begin{array}{c}\text { DLC per } \\
\text { equipment }\end{array}$ & $\begin{array}{c}\text { X events per } \\
\text { month }\end{array}$ \\
\hline $\begin{array}{l}\text { DLC } \\
\text { T2 }\end{array}$ & M & Cost/kWh reduced & $\begin{array}{c}\text { DLC per } \\
\text { equipment }\end{array}$ & $\begin{array}{c}\text { Actual } \mathrm{kWh} \\
\text { reduction }\end{array}$ \\
\hline $\begin{array}{l}\text { DLC } \\
\text { T3 }\end{array}$ & $\mathrm{M}$ & $\begin{array}{c}\text { N/A } \\
\text { (Reduced/Increased } \\
\text { energy costs) }\end{array}$ & $\begin{array}{c}\text { DLC per } \\
\text { equipment }\end{array}$ & N/A \\
\hline $\begin{array}{l}\text { Red. } \\
\text { T1 }\end{array}$ & $\mathrm{V}$ & $\begin{array}{c}\text { Cost/kWh reduced } \\
\text { Reduction } \\
\text { notification }\end{array}$ & $\begin{array}{c}\text { Actual } \mathrm{kWh} \\
\text { reduction }\end{array}$ \\
\hline $\begin{array}{l}\text { Red. } \\
\text { T2 }\end{array}$ & $\mathrm{M}$ & $\begin{array}{c}\text { Actual } \\
\text { Cost/kWh reduced } \\
\text { consumption } \\
\text { level notification }\end{array}$ & $\begin{array}{c}\text { Actual } \mathrm{kWh} \\
\text { reduction }\end{array}$ \\
\hline $\begin{array}{l}\text { Pricin } \\
\text { g T1 }\end{array}$ & $\mathrm{V}$ & $\begin{array}{c}\text { N/A } \\
\text { (Reduced/Increased } \\
\text { energy costs })\end{array}$ & $\begin{array}{c}\text { Electricity price } \\
\text { notification }\end{array}$ & N/A \\
\hline
\end{tabular}

If a community member establishes contract with the CM for the DLC T1 program, it will give permission to the CM to directly control the equipment somehow that the type of the equipment and the number of events per month are specified in the contract. In exchange, the community member receives the fixed incentives specified in the contract. For the DLC T2 program, the $\mathrm{CM}$ is able to directly control the equipment whenever it witnesses with critical periods, for instance while it faces with a technical or economic reason. For this purpose, the member will be notified before the event, and receive the incentives based on the $\mathrm{kWh}$ reduction. Regarding the DLC T3 program, the member gives permission to the $\mathrm{CM}$ to directly control the equipment if the electricity price is greater than the value specified in the contract. In this condition, the member will be informed before the event, and will not receive any incentives.

Additionally, if the member has contract with the CM for Red. T1, while the CM decides to apply the DR event, the member will be notified for the amount of consumption reduction, and if it accepted to participate, it receives the incentives based on the $\mathrm{kWh}$ reduction. In the Red. T2 program, the member is notified with the actual consumption level before the event, and they should keep their consumption on that specific level during the event. Also in this program, the member receives incentive based on the $\mathrm{kWh}$ reduction.

The last DR contract that the community members can establish with the CM, is Pricing T1. In this contract, the member specifies a value of electricity price somehow that if the electricity price raises and be greater than that specific value, then it will decrease the consumption as much as it specified in the contract. This means the member will be notified with the real-time electricity price, and if it agreed to participate, it will reduce the consumption. In the Pricing T1 program, the member will not own any incentive for their consumption reduction.

\section{CASE STUdy}

In this section of the paper, a case study will be developed in order to test and validate the proposed community model. For this purpose, a distribution network of a university campus is considered as the community grid. This university campus microgrid has been adapted from [11] and is shown on Fig. 2. This distribution network consists of the underground electrical lines with 21 buses, which a MV/LV transformer located in BUS \#21 connects the microgrid to the main network, with the following features: $15 \mathrm{kV} / 400 \mathrm{~V}-230 \mathrm{~V}$, $2050 \mathrm{kVA}$. In fact, the distribution transformer in BUS \#21, is the connection point of the CM and the electricity markets.

There are 20 buildings in the university campus microgrid indicating with the yellow color in Fig. 2, somehow each of which is connected to one bus of the network. Therefore, each building can be considered as a member of the community model presented in this paper. We took into account that there are 17 prosumers, 4 producers, and 3 consumers. The prosumers consist of 7 residential houses, 7 commerce facilities, and 3 factories that all of them are equipped with PV system. The producers include 3 PV stations, and one wind turbine, and finally, the consumers are three residential houses. 


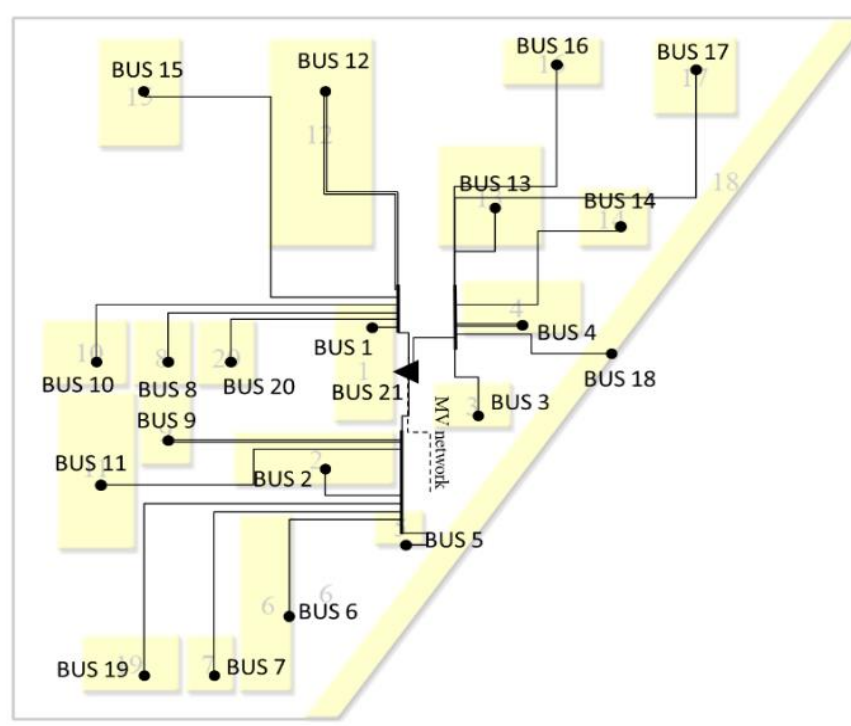

Fig. 2. The low voltage distribution network porposed for the community model.

Table 2 shows the details of the established DR contracts between the CM and members. In this case study, each community member is indicated by a specific ID number.

Table 2. The DR contracts of the community members ( $\mathrm{H}=$ House; $\mathrm{C}=$ Commerce; $\mathrm{F}=$ Factory).

\begin{tabular}{|c|c|c|c|c|c|c|c|c|}
\hline \multirow{3}{*}{ ID } & \multirow{3}{*}{ Time } & \multicolumn{6}{|c|}{ DR Contracts (kW) } & \multirow[t]{3}{*}{$\begin{array}{c}\text { TOTAL } \\
(\mathbf{k W})\end{array}$} \\
\hline & & \multicolumn{3}{|c|}{$D L C$} & \multicolumn{2}{|c|}{ Red. } & \multirow{2}{*}{$\begin{array}{c}\text { Pricing } \\
T 1 \\
\end{array}$} & \\
\hline & & $T 1$ & $T 2$ & T3 & $T 1$ & $T 2$ & & \\
\hline $\begin{array}{c}1 \\
(\mathrm{H})\end{array}$ & $10-24$ & 3.3 & & & 4.9 & & & 8.2 \\
\hline $\begin{array}{c}2 \\
(\mathrm{H})\end{array}$ & $12-24$ & & 10.1 & & & & & 10.1 \\
\hline $\begin{array}{c}3 \\
(\mathrm{H}) \\
\end{array}$ & 13-19 & & & & 5.4 & & 1.2 & 6.6 \\
\hline $\begin{array}{c}4 \\
(\mathrm{~F}) \\
\end{array}$ & $8-23$ & & & 9.7 & & 21.6 & & 31.3 \\
\hline $\begin{array}{c}5 \\
(\mathrm{H}) \\
\end{array}$ & - & - & - & - & - & - & - & - \\
\hline $\begin{array}{c}6 \\
(\mathrm{C}) \\
\end{array}$ & $9-23$ & 6.8 & & & & & 3.9 & 10.7 \\
\hline $\begin{array}{c}7 \\
(\mathrm{C}) \\
\end{array}$ & $10-20$ & & & & 17.6 & & & 17.6 \\
\hline $\begin{array}{c}8 \\
(\mathrm{~F}) \\
\end{array}$ & $9-19$ & & 18.4 & & 7.5 & & & 25.9 \\
\hline $\begin{array}{c}9 \\
(\mathrm{C}) \\
\end{array}$ & $9-18$ & & & 15.4 & & & & 15.4 \\
\hline $\begin{array}{l}10 \\
(\mathrm{C}) \\
\end{array}$ & - & - & - & - & - & - & - & - \\
\hline $\begin{array}{l}11 \\
(\mathrm{~F})\end{array}$ & $10-23$ & & & & & & 28.5 & 28.5 \\
\hline $\begin{array}{l}12 \\
(\mathrm{C})\end{array}$ & $12-22$ & & & & & 16.3 & & 16.3 \\
\hline $\begin{array}{l}13 \\
(\mathrm{C}) \\
\end{array}$ & $12-17$ & & 18.1 & & & & & 18.1 \\
\hline $\begin{array}{l}14 \\
(\mathrm{H})\end{array}$ & $15-24$ & & & 5.2 & & & & 5.2 \\
\hline $\begin{array}{l}15 \\
(\mathrm{H})\end{array}$ & $12-24$ & 0.9 & & & & 0.6 & & 1.5 \\
\hline $\begin{array}{l}16 \\
(\mathrm{H})\end{array}$ & $12-24$ & 2.5 & & & & & 1.6 & 4.1 \\
\hline $\begin{array}{l}17 \\
(\mathrm{C})\end{array}$ & $10-18$ & & & & 15.8 & & & 15.8 \\
\hline $\begin{array}{l}18 \\
(\mathrm{H}) \\
\end{array}$ & - & - & - & - & - & - & - & - \\
\hline $\begin{array}{l}19 \\
(\mathrm{H})\end{array}$ & $9-24$ & & & & & & 6.4 & 6.4 \\
\hline $\begin{array}{l}20 \\
(\mathrm{H})\end{array}$ & $13-24$ & 3.7 & & & & 1.2 & & 4.9 \\
\hline \multicolumn{2}{|c|}{ TOTAL $(\mathrm{kW})$} & 17.2 & 46.6 & 30.3 & 51.2 & 39.7 & 41.6 & 226.6 \\
\hline
\end{tabular}

In Table 2, members \#1 to \#17 are all prosumers and \#18, $\# 19$, and \#20 are only consumers. Also, as you can see in Table 2, there are 24 periods considered for the case study, and each member specified the periods and the programs that tends to participate. As an example, member \#4 participates in two DR programs-DLC T3 and Red. T2- starts from period 8 to 23. The incentives for these DR programs are contractual and is constants for all type of the members, however, the price of buying energy from the CM for each member is different and is based on its type. All the prices used in this case study are shown on Table 3.

Table 3. The prices of the energy transactions between the members and CM. (All values are in EUR/kWh)

\begin{tabular}{|l|c|c|c|c|c|c|}
\hline \multirow{2}{*}{ Type } & \multicolumn{5}{|c|}{ Incentives } & \multicolumn{2}{c|}{ Member } \\
\cline { 2 - 7 } & DLC T1 & DLC T2 & Red. T1 & Red. T2 & Buy & Sell \\
\hline House & 0.03 & 0.04 & 0.02 & 0.03 & 0.1 & 0.03 \\
\hline Commerce & 0.03 & 0.04 & 0.02 & 0.03 & 0.08 & 0.03 \\
\hline Factory & 0.03 & 0.04 & 0.02 & 0.03 & 0.06 & 0.03 \\
\hline Producer & - & - & - & - & - & 0.03 \\
\hline
\end{tabular}

The price of the market, where the CM should buy energy from that when it faces with the lack of resources for the member's demand, is considered as $0.05 \mathrm{EUR} / \mathrm{kWh}$. Therefore, it is affordable for the CM to apply DR and pay the incentives to the member in order to reduce their consumption comparing to purchase energy from the market.

Additionally, the CM always tends to use the most cheaper resources to feed the loads in order to decrease its operation cost. For instance, as Table 1 demonstrated, DLC T3 and Pricing T1 programs are the two resources the CM applies to the members, since they have no incentive payment from CM stand point. Therefore, the proposed optimization methodology will be executed by the CM in order to minimize its operation costs.

This optimization problem is a single period optimization and has been solved through the several decision trees implemented by classregtree function of MATLAB ${ }^{\mathrm{TM}}$, where the following representative scenario parameters are provided as inputs:

$\mathbf{x 1 : ~ T o t a l ~ c o n s u m p t i o n ~ o f ~ t h e ~ c o m m u n i t y ; ~}$

x2: Scheduled DRERs; x3: Scheduled DR resources;

x4: Max DLC T1 capacity; x5: Max DLC T2 capacity;

x6: Max DLC T3 capacity; x7: Max Red. T1 capacity;

x8: Max Red. T2 capacity; x9: Max Pricing T1 capacity;

x10: DRER Price; x11: Market Price.

The results of the optimization process are shown on Fig. 3 for the member \#1, and on Table 4 for the rest of members.

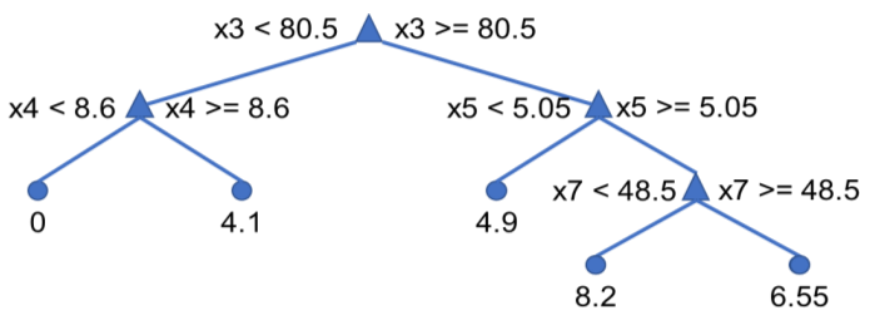

Fig. 3. Decision tree of DR resources scheduling for member \#1 (All values are in $\mathrm{kW}$ ). 
Table 4. DR resources scheduling decisions for all members. ( $\mathrm{H}=$ House; $\mathrm{C}=$ Commerce; $\mathrm{F}=$ Factory).

\begin{tabular}{|c|c|c|c|c|c|c|c|c|c|c|}
\hline Decision & \multicolumn{10}{|c|}{ Decision Basis } \\
\hline & $\boldsymbol{x} \mathbf{1}$ & $\boldsymbol{x} 2$ & $\boldsymbol{x} \mathbf{3}$ & $\boldsymbol{x} \mathbf{4}$ & $\boldsymbol{x} \mathbf{5}$ & $\boldsymbol{x} \mathbf{6}$ & $\boldsymbol{x} \mathbf{7}$ & $\boldsymbol{x} \mathbf{8}$ & $\boldsymbol{x} \mathbf{9}$ & $\boldsymbol{x 1 0 - \boldsymbol { 1 1 1 }}$ \\
\hline $2(\mathrm{H})$ & $\mathrm{X}$ & & & $\mathrm{X}$ & & & & & & \\
\hline $3(\mathrm{H})$ & $\mathrm{X}$ & & & & $\mathrm{X}$ & & & & & \\
\hline $4(\mathrm{~F})$ & & $\mathrm{X}$ & & & & & & $\mathrm{X}$ & & \\
\hline $6(\mathrm{C})$ & & $\mathrm{X}$ & & $\mathrm{X}$ & & & & & & \\
\hline $7(\mathrm{C})$ & & & & & & $\mathrm{X}$ & & & & \\
\hline $8(\mathrm{~F})$ & & & & & $\mathrm{X}$ & & & & & \\
\hline $9(\mathrm{C})$ & & & & & & $\mathrm{X}$ & & & & \\
\hline $11(\mathrm{~F})$ & & & & & & & & & $\mathrm{X}$ & \\
\hline $12(\mathrm{C})$ & & & $\mathrm{X}$ & & & & & & & \\
\hline $13(\mathrm{C})$ & & $\mathrm{X}$ & & & & & & & & \\
\hline $14(\mathrm{H})$ & & $\mathrm{X}$ & & $\mathrm{X}$ & & & & & & \\
\hline $15(\mathrm{H})$ & & & $\mathrm{X}$ & $\mathrm{X}$ & $\mathrm{X}$ & & $\mathrm{X}$ & & & \\
\hline $16(\mathrm{H})$ & $\mathrm{X}$ & $\mathrm{X}$ & & $\mathrm{X}$ & & & & & & \\
\hline $17(\mathrm{C})$ & $\mathrm{X}$ & $\mathrm{X}$ & & & & & & & & \\
\hline $19(\mathrm{H})$ & $\mathrm{X}$ & & & & & & & & & \\
\hline $20(\mathrm{H})$ & & $\mathrm{X}$ & & $\mathrm{X}$ & & & & & & \\
\hline
\end{tabular}

Actually, Fig. 3 illustrates the possible conditions that if happened, the CM applies the contractual DR for member \#1 with the specific value of reduction/curtailment. A decision tree similar to Fig. 3 is also provided by the optimization process for each member. However, due to the lack of space, only the decision basis of each tree for each member is shown on Table 4. Moreover, Fig. 4 presents the scheduling of the resources during the 24 periods of the case study, and Fig. 5 demonstrates the detailed scheduling for one period.

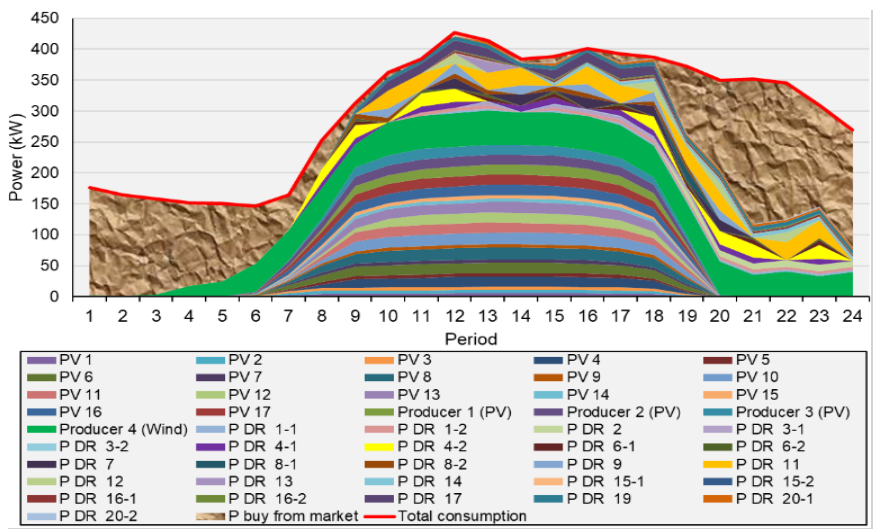

Fig. 4. Resource scheduling results for 24 periods.

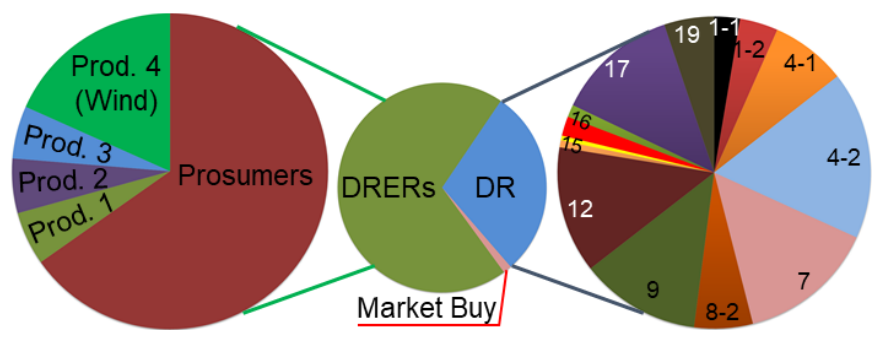

Fig. 5. The detailed resource scheduling results for period \#12.

As Fig. 4 shows, there are several periods that CM purchased energy from the market since the load demand is greater than the local energy resources. Also, in Fig. 5, the total consumption of the community was supplied by: $70 \%$ DRERs, 29\% DR resources, and 1\% external suppliers (purchased from the market). For the DRERs, 65\% is relevant to the prosumers generation, $5 \%$ is for producer $1(\mathrm{PV}), 6 \%$ for producer $2(\mathrm{PV}), 5 \%$ for producer $3(\mathrm{PV})$, and $19 \%$ is for the producer 4 (wind). Moreover, the detailed DR scheduled resources for all community members, who participate in the DR programs, are shown on the right side of Fig 5, where 52\% is for commerce participation, $32 \%$ for the factories, and $16 \%$ is for the residential houses.

\section{CONCLUSIONS}

In this paper, a smart community grid model was presented that includes different type of members, such as consumers, producers, and prosumers, somehow most of them have contract with a central controller unit called community manager. The main focus of the paper was to minimize the operation costs of the community manager by applying different types of demand response programs and the use of renewable energy resources. A single period optimization algorithm was developed for this purpose. In the case study, a distribution network of a real university campus was used as the community grid, and the proposed optimization methodology was applied during 24 periods. The results of case study validate the advantages of the proposed community model, and how the integration and the use of renewable resources and demand response programs can benefit both sides of the network.

\section{REFERENCES}

[1] J. Hu, J. Cao, T. Yong, J. Guerrero, M. Chen and Y. Li, "Demand Response Load Following of Source and Load Systems", IEEE Trans. on Control Systems Technology, vol. 25, no. 5, pp. 1586-1598, 2017.

[2] A. Nisar and M. Thomas, "Comprehensive Control for Microgrid Autonomous Operation With Demand Response", IEEE Trans. on Smart Grid, vol. 8, no. 5, pp. 2081-2089, 2017.

[3] O. Abrishambaf, P. Faria, L. Gomes, J. Spínola, Z. Vale and J. Corchado, "Implementation of a Real-Time Microgrid Simulation Platform Based on Centralized and Distributed Management", Energies, vol. 10, no. 6, p. 806, 2017.

[4] O. Abrishambaf, M. Ghazvini, L. Gomes, P. Faria, Z. Vale and J. Corchado, "Application of a Home Energy Management System for Incentive-Based Demand Response Program Implementation", 2016 27th International Workshop on Database and Expert Systems Applications (DEXA), 2016.

[5] S. Kwon, L. Ntaimo and N. Gautam, "Optimal Day-Ahead Power Procurement With Renewable Energy and Demand Response", IEEE Trans. on Power Systems, vol. 32, no. 5, pp. 3924-3933, 2017.

[6] P. Faria, J. Spinola and Z. Vale, "Aggregation and Remuneration of Electricity Consumers and Producers for the Definition of DemandResponse Programs", IEEE Trans. on Industrial Informatics, vol. 12, no. 3, pp. 952-961, 2016.

[7] S. Salinas, M. Li and P. Li, "Multi-Objective Optimal Energy Consumption Scheduling in Smart Grids," IEEE Trans. on Smart Grid, vol. 4, no. 1, pp. 341-348, 2013.

[8] P. Palensky and D. Dietrich, "Demand Side Management: Demand Response, Intelligent Energy Systems, and Smart Loads," IEEE Trans. on Industrial Informatics, vol. 7, no. 3, pp. 381-388. 2011.

[9] B. Canizes, M. Silva, P. Faria, S. Ramos and Z. Vale, "Resource scheduling in residential microgrids considering energy selling to external players," 2015 Clemson University Power Systems Conference (PSC), 2015.

[10] O. Abrishambaf, P. Faria, João Spínola, and Z. Vale, "An Aggregation Model for Energy Resources Management and Market Negotiations," Advances in Science, Technology and Engineering Systems Journal, vol. 3, no. 2, pp. 231-237, 2018.

[11] M. Silva, F. Fernandes, H. Morais, S. Ramos and Z. Vale, "Hour-ahead energy resource management in university campus microgrid", 2015 IEEE Eindhoven PowerTech, 2015. 